\title{
Articulações Teóricas entre Ensino de Ciências Naturais e Direitos Humanos: Proposta para uma Perspectiva de Formação Humana
}

\section{Theoretical Links Between Natural Sciences Teaching and Human Rights: Proposals for a Humane Formation Perspective}

\author{
Hanslivian Correia Cruz Bonfim ${ }^{\circledR}$ Brasil \\ Orliney Maciel Guimarães ${ }^{\circledR}$ Brasil
}

\begin{abstract}
Neste artigo teórico, discutimos sobre as formas de articular a temática Direitos Humanos ao ensino de Ciências Naturais nos anos iniciais do ensino fundamental, em uma perspectiva voltada para a formação humana. A fundamentação teórica para aprofundar a discussão da temática proposta foi realizada por meio de pesquisa bibliográfica, tendo como fontes: livros, artigos científicos e documentos oficiais. A partir desta pesquisa, propusemos algumas temáticas que se aproximam dos direitos humanos e que são possíveis de se articularem com os conteúdos de Ciências Naturais desenvolvidos nos anos iniciais. Consideramos que estas temáticas precisam estar baseadas em eixos estruturantes que irão fundamentar o trabalho pedagógico do(a) professor(a) para que este(a) tenha como propósito a formação humana dos(as) educandos(as), esses eixos são: Sensibilizar-se no reconhecimento das diferenças sociais, culturais e econômicas; Reconhecer-se como cidadão(ã) de direitos e respeitar o direito do "outro"; Planejar e desenvolver práticas inclusivas; Valorizar a inter-relação entre seres humanos e ambientes naturais. Consideramos que o trabalho pedagógico voltado para esta perspectiva precisa basear-se em uma metodologia dialógica e participativa, tendo como ênfase a formação humana e cidadã.
\end{abstract}

Palavras-chave: Ciências Naturais; Direitos Humanos; Formação humana; Ensino Fundamental.

In this theoretical article, we discuss the ways of articulating Human Rights and the teaching of Natural Sciences in the early years of elementary school, in a perspective focused on humane formation. The theoretical basis for further discussion of the proposed subject matter was carried out through bibliographic research, having as sources: books, theses, dissertations, scientific articles and official documents. From this research, we proposed some themes that are related to human rights and are possible 
to be articulated with the contents of Natural Sciences developed in the early years. We consider that these themes need to be based on structuring axes that will base the pedagogical work of the teachers, so that they have as purpose the humane education of the students. These axes are: to be sensitized in the recognition of social, cultural and economic differences; to recognize yourself as a citizen with rights and to respect the right of the other; to plan and develop inclusive practices; to value the interrelationship between human beings and natural environments. We consider that the pedagogical work aimed at this perspective needs to be based on a dialogical and participatory methodology, with an emphasis on a humane education.

Keywords: Natural Sciences; Human rights; Humane formation; Elementary School.

\section{Introdução}

Os Direitos Humanos são considerados direitos fundamentais da pessoa humana, bem como trata-se daqueles "direitos mínimos para que o homem viva em sociedade" (Siqueira Júnior \& Oliveira, 2010, p. 22). A violação dos direitos humanos pode ser constatada em diferentes instituições, como famílias, órgãos públicos, igrejas e até mesmo na escola (MEC, 2012). Na escola podemos perceber várias situações que se relacionam às questões de falta de respeito, de intolerância e falta de empatia, gerando, muitas vezes, a violência entre estudantes e estudantes-professores(as). As questões voltadas ao não cumprimento dos direitos humanos na sociedade tornam-se evidentes quando observadas de modo mais atento, levando à constatação que, muitas vezes, são naturalizadas e não são percebidas como violações à dignidade humana, a qual consiste em um princípio dos Direitos Humanos. Diante desse tema de urgência social, consideramos fundamental que temáticas que se referem aos Direitos Humanos sejam discutidas nas diferentes disciplinas, não apenas nas disciplinas das áreas humanas e sociais, mas também na área da ciência da natureza, porque avaliamos que muitos conteúdos das disciplinas que contemplam essa área são possíveis de se articularem com as temáticas voltadas aos direitos humanos.

Assim, este artigo se refere a uma parte de uma pesquisa de doutorado que está em desenvolvimento. Portanto, é uma produção teórica embasada em pesquisa bibliográfica, tendo como fontes: livros, publicações em periódicos e documentos oficiais (Carvalho et. al., 2019), a fim de atingir o objetivo da investigação, que consiste em discutir formas de articular temáticas voltadas para os direitos humanos e Ciências Naturais nos anos iniciais do ensino fundamental, numa perspectiva voltada para a formação humana, fundamentada numa educação em direitos humanos. A primeira etapa desta pesquisa bibliográfica consistiu em buscar informações no documento Diretrizes Curriculares Nacionais para Educação em Direitos Humanos (MEC, 2012), a fim de compreender o que este documento preconiza sobre o trabalho pedagógico voltado à Educação em Direitos Humanos (EDH) na educação básica. Após esta etapa, o objetivo foi articular a EDH e o currículo, com o propósito de depreender sobre as várias questões que precisam ser 
ponderadas quando se reflete sobre um currículo que tem por base o multiculturalismo e uma EDH. Esta etapa foi fundamentada a partir dos autores (as): Arroyo (2013); Candau (2008, 2013); Lopes e Macedo (2011); Moreira e Silva (2005); Moreira e Candau (2007); Silva (2005) e Silva (2014), os quais consideramos referências importantes quando se discute questões relacionadas ao multiculturalismo, numa visão intercultural, e direitos humanos. A última etapa consistiu em discutir a articulação do ensino de Ciências Naturais nos anos iniciais aos Direitos Humanos, a qual foi fundamentada a partir dos autores que discutem o ensino de Ciências e a formação para a cidadania; e alguns autores que trabalham com o ensino e Ciências nos anos iniciais: Chassot (2000); Fabri e Silveira (2013); Lorenzetti e Delizoicov (2001); Oja e Bastos (2013); Porto e Porto (2012); Soares, Mauer e Kortmann (2013); Viecheneski e Carletto (2013); bem como autores que defendem formas de desenvolver a escuta sensível nos anos inicias (Arroyo, 2013; Oliveira, 2013). A partir destes autores, apresentamos sugestões de temáticas que consideramos possíveis de serem desenvolvidas nesta etapa da escolarização e que fazem interface com os Direitos Humanos. Nesta última etapa, também propusemos alguns eixos estruturantes que compreendemos serem importantes de estarem presentes nestas discussões para uma educação voltada à formação humana.

Consideramos que a educação tem como objetivo não apenas a formação cognitiva do indivíduo, mas também sua formação humana e cidadã. Formar indivíduos mais solidários, mais tolerantes, respeitosos e que tenham a capacidade de se colocarem no lugar do outro, também é função da escola. Para isso, é fundamental que as discussões sobre esse tema sejam pensadas e planejadas na instituição de ensino, inclusive nas aulas de Ciências Naturais nos anos iniciais do Ensino Fundamental.

Este artigo está dividido nos seguintes tópicos: Educação em Direitos Humanos e Currículo; O ensino de Ciências Naturais e Direitos Humanos e, por fim, as considerações finais.

\section{Educação em Direitos Humanos (EDH) e Currículo}

Partimos da premissa de que é importante compreender as transformações da sociedade ao longo da história, pois estas mudanças originam novas demandas para a educação escolar, e que, portanto, as práticas desenvolvidas nas instituições de ensino precisam estar coerentes com estas transformações. Imbernón (2016) explica que, “[...] ao longo do século XX e até ao atual momento do século XXI, a sociedade tornou-se mais complexa, portanto, exercer a função de professor também assumiu grandes parcelas de complexidade [...]” (p. 34). Esse autor também considera que tanto as funções do(a) professor(a) da educação básica quanto os(as) estudantes mudaram ao longo da história, e o mesmo aconteceu com a sociedade em que estamos inseridos. Nesse sentido, o autor ressalta que:

Das velhas funções de instruir as crianças nas quatro operações e aprender a ler e a escrever passou-se a uma educação mais ampla, mais completa, que abarca todos os aspectos das crianças: físicos, emocionais, intelectuais, sociais.... Os professores já não 
são aquelas pessoas que, recorrendo a um livro único ou enciclopédico (para todas as matérias), ensinavam as questões básicas para poder ter acesso à cultura. No século XXI, eles se converteram em profissionais da educação e do conhecimento, porque as questões sociais são muito importantes. (Imbernón, 2016, p. 51).

Para esse autor, muitos aspectos da sociedade são necessários de ser aprendidos e compreendidos no contexto escolar. Ele também pontua que neste espaço é importante desenvolver o respeito em relação a si mesmo e também em relação aos outros, sejam eles quem forem, bem como o respeito pelo ambiente em que vivem. Consideramos que estas questões são importantes para a formação cidadã e humana do estudante. Imbernón (2016) complementa que será fundamental desenvolver nos professores e nas crianças "o respeito e a tolerância, dois conceitos que terão um papel fundamental no mundo que construímos dia a dia" (Imbernón, 2016, p. 52). Mas como desenvolver esses conceitos no ensino de Ciências Naturais nos anos iniciais do ensino fundamental? Consideramos que, muitas vezes, os conteúdos desenvolvidos nos anos iniciais em Ciências Naturais se resumem nos conteúdos conceituais, sendo que as questões sociais, culturais e políticas são deixadas para os(as) professores(as) que atuam nos componentes curriculares voltados para a área humana e social. No documento Diretrizes Nacionais para a Educação em Direitos Humanos (MEC, 2012) é destacado que a Educação em Direitos Humanos:

[...] se destina a formar crianças, jovens e adultos para participar ativamente da vida democrática e exercitar seus direitos e responsabilidades na sociedade, também respeitando e promovendo os direitos das demais pessoas. É uma educação integral que visa o respeito mútuo, pelo outro e pelas diferentes culturas e tradições. (MEC, 2012, p. 496).

No documento supracitado, fica explícito que a Educação em Direitos Humanos "precisa atravessar os currículos, relações cotidianas, gestos, 'rituais pedagógicos', modelos de gestão" (MEC, 2012, p. 501). Ainda complementa que uma das formas para sua efetivação no contexto educacional também pode acontecer mediante a (re)produção de conhecimentos relacionados para a defesa e promoção dos direitos humanos. O propósito principal da Educação em Direitos Humanos está voltado para a formação ética, crítica e política dos estudantes.

O documento Diretrizes Curriculares Nacionais para Educação Básica (MEC, 2013) destaca que, visando alcançar a inclusão social, a educação escolar precisa estar fundamentada na "ética e nos valores da liberdade, na justiça social, na pluralidade, na solidariedade e na sustentabilidade" (p. 16), para que se atinja o pleno desenvolvimento dos educandos, em todas as dimensões contribuindo para a formação de cidadãos conscientes de seus direitos e deveres e que sejam comprometidos com a transformação social.

Para McCowan (2015), uma EDH poderá contribuir para que as pessoas mudem de atitudes e de comportamentos, pois "um indivíduo pode desenvolver respeito pelas opiniões dos outros, reconhecer os interesses daqueles que estão fora da sua comunidade 
imediata, grupo étnico ou nacionalidade, e abster-se de submeter os outros, por exemplo, à agressão física ou humilhação psicológica" (p. 34). O autor também destaca que a EDH poderá ser entendida como um meio para se defender os direitos humanos do educando em si, ou seja, "a aquisição de informações sobre os instrumentos de direito internacional, o desenvolvimento de habilidades de comunicação para negociar com as autoridades competentes e as disposições para agir corajosamente em defesa de seus direitos" (p. 34). É importante ressaltar que uma educação em direitos humanos abarcará tanto a capacidade dos indivíduos de defender e exercer seus direitos, como também o de respeitar e estar em ação a favor dos direitos dos outros. Nesse sentido, "a EDH torna-se um direito de todos e não apenas dos mais excluídos (embora a necessidade destes últimos possa aparecer com uma demanda mais imediata). A construção de uma cultura de direitos humanos implica o envolvimento de todos na aprovação dos direitos" (McCowan, 2015, p. 37).

As Diretrizes Curriculares Nacionais para Educação Básica (MEC, 2013) destacam o Cuidar e o Educar como duas ações indissociáveis para que se tenha como objetivo a formação humana, tendo como centro da educação o estudante. Sendo assim, o educar e o cuidar se iniciam na primeira etapa da educação básica e precisam se estender até o Ensino Médio e estudos posteriores. Cuidar e educar significa compreender que o direito à educação parte do princípio da formação da pessoa em sua essência humana. Nessa perspectiva, o cuidar deve ser considerado no sentido de acolher a todos os educandos, independentemente de sua faixa etária e condição física, social e cultural, "com o respeito e, com atenção adequada, de estudantes com deficiência, jovens e adultos defasados na relação idade-escolaridade, indígenas, afrodescendentes, quilombolas e povos do campo" (MEC, 2013, p. 17). Além disso, o "educar com cuidado significa aprender a amar sem dependência, desenvolver a sensibilidade humana na relação de cada um consigo, com o outro e com tudo o que existe, com zelo, ante uma situação que requer cautela em busca da formação humana plena” (MEC, 2013, p. 17).

Esta visão de educação, fundamentada nestas duas ações indissociáveis, vai ao encontro de uma Educação voltada para os Direitos Humanos, em uma perspectiva “intercultural” (Candau, 2013). Pois nesta visão, o educar e o cuidar tem como princípios norteadores, o reconhecimento do "outro", o respeito a si mesmos e aos outros, a tolerância, a ética, a cooperação, a solidariedade e a alteridade, que são questões fundamentais para se viver em uma coletividade. Assim, o escopo da Educação em Direitos Humanos é que o indivíduo e/ou grupo social se conheça como pessoa que possui direitos, bem como "seja capaz de exercê-los e promovê-los ao mesmo tempo em que reconheça e respeite os direitos do outro. A EDH busca também desenvolver a sensibilidade ética nas relações interpessoais, em que cada indivíduo seja capaz de perceber o outro em sua condição humana" (MEC, 2012, p. 503).

Nesta perspectiva, o processo educativo tem um papel importante para a construção humana em todas as suas dimensões, no sentido de ter uma educação voltada para a formação cidadã, pessoas que sejam capazes de atuar em seu contexto 
social, com autonomia e liberdade, além de tomar decisões e participar das decisões públicas do país.

Neste artigo defendemos uma educação voltada para os Direitos Humanos cujo cerne seja o educar e o cuidar como duas ações indissociáveis, complementares e importantes de estarem presentes no contexto escolar, uma educação que seja inclusiva e promotora de aprendizagens. As escolas podem ser consideradas como microcosmos sociais, nas quais as diversidades se encontram. Pois, nestes contextos estão presentes diferentes formas de ver o mundo, distintos valores e necessidades, diferenças econômicas, sociais e culturais e várias crenças. E o convívio com esta diversidade pode gerar conflitos, os quais são inseparáveis à convivência humana. Nesse sentido, as instituições educacionais precisam analisar de forma crítica essa realidade, possibilitando que diferentes formas de ver o mundo se aproximem e se confrontem, mediante "processos democráticos e procedimentos éticos e dialógicos, visando sempre o enfrentamento das injustiças e das desigualdades" (MEC, 2012, p. 504). Consideramos que, dessa forma, a escola contribuirá para formar pessoas críticas e com capacidade para analisar e avaliar a realidade, tendo como princípio os Direitos Humanos. Silva (2014) destaca que o “[...] desafio que hoje se coloca para uma educação em direitos humanos parece ser o de construir um currículo que nos permita sair da lógica que ensina a diversidade para avançar na consolidação de uma prática que vivencia a diversidade” (p. 43).

Nesse sentido, consideramos que Direitos Humanos deveria ser um tema importante para estar presente no currículo escolar, sendo vivido nas instituições escolares, por estudantes, funcionários, professores e famílias.

Em relação ao currículo, Moreira e Silva (2005) destacam que este deixou de ser visto apenas em uma perspectiva técnica, relacionado apenas aos procedimentos e métodos, e defendem que se pode falar atualmente de uma "tradição crítica do currículo, guiada por questões sociológicas, políticas, epistemológicas” (p. 7). Neste sentido, existe um questionamento voltado para o porquê das formas de organização do conhecimento escolar. Para Apple (2005), o currículo não pode ser considerado como um conjunto de conhecimentos neutros, resultante de uma seleção cultural de um indivíduo ou da visão de um determinado grupo sobre o que é conhecimento legítimo. Assim, pode se considerar o currículo como "um artefato social e cultural. Isso significa que ele é colocado na moldura mais ampla de suas determinações sociais, de sua história, de sua produção contextual” (Moreira \& Silva, 2005, p. 7). Portanto, o currículo não pode ser considerado como neutro ou inocente em relação à transmissão do conhecimento escolar. Nesse sentido, o currículo não pode ser analisado sem levar em conta a sua constituição social e histórica. Assim, o conhecimento organizado para ser transmitido nas escolas, "passa a ser visto não apenas como implicado na produção de relações assimétricas de poder no interior da escola e da sociedade, mas também como histórica e socialmente contingente" (Moreira \& Silva, 2005, p. 21). Para Silva (2005), quando se pensa em currículo, não se pode esquecer de que o conhecimento que o constitui está envolvido "naquilo que somos, naquilo que nos tornamos, na nossa identidade, na 
nossa subjetividade. Talvez possamos dizer que, além de uma questão de conhecimento, o currículo é também uma questão de identidade" (p. 16). Nesta mesma perspectiva, Moreira e Candau (2007) afirmam que:

[...] as discussões sobre o currículo incorporam, com maior ou menor ênfase, discussões sobre os conhecimentos escolares, sobre os procedimentos e as relações sociais que conformam o cenário em que os conhecimentos se ensinam e se aprendem, sobre as transformações que desejamos efetuar nos alunos e alunas, sobre os valores que desejamos inculcar e sobre as identidades que pretendemos construir. (Moreira \& Candau, 2007, p. 18).

Portanto, é importante destacar que, quando se discute currículo, discutem-se também questões voltadas para a identidade, para a diferença, pois o currículo se refere à formação humana.

Candau (2013) pontua que questões referentes à educação e à cultura são importantes para serem problematizadas, e destaca que a característica da escola, como sendo homogênea e monocultural, ainda se apresenta forte no contexto atual, mas que também há uma consciência da importância de se romper com esta característica e construir práticas educativas que sejam mais voltadas para diferença e para o multiculturalismo. Para Lopes e Macedo (2011), o multiculturalismo pode ser considerado como "descrição da sociedade contemporânea" (p. 187), e que pode ser compreendido para indicar a característica "plural das sociedades ocidentais contemporâneas" (Moreira, 2002, p. 16), situação do mundo atual, que não se pode desconsiderar.

Na perspectiva voltada para a ideia do multiculturalismo, a escola deve ser vista como um espaço de "entrecruzamento de culturas, fluido e complexo, atravessado por tensões e conflitos" (Candau, 2013, p. 14). Esta autora, ainda, complementa que, ao pensar a escola dessa forma, é necessário refletir sobre os "diferentes componentes e romper com a tendência homogeneizadora e padronizada que impregna suas práticas" (Candau, 2013, p. 16).

Candau (2013) afirma que os(as) docentes não podem ignorar as questões culturais, as quais estão presentes no contexto escolar, pois, se houver esse desconhecimento, como consequência pode-se ter uma escola cada vez mais distante das questões simbólicas e subjetivas dos(as) estudantes. Arroyo (2020) explica que, no currículo escolar, muitas vezes, "as experiências humanas e a diversidade de seus sujeitos é ignorada, apenas algumas experiências, alguns sujeitos e conhecimentos são considerados válidos, universais, legítimo" (p.77), e que seria fundamental - e concordamos com este autor - a inclusão nos currículos escolares das experiências sociais dos agentes envolvidos no processo educativo, tornando a escola um espaço de inclusão e não de segregação. O Brasil apresenta uma configuração própria em relação ao multiculturalismo, pois o país é constituído por uma base multicultural forte, em que as relações interétnicas se mostram constantes ao se analisar a história, a qual foi dolorosa, principalmente, quando se trata dos grupos indígenas e afrodescendentes. Deste modo, compreende-se que a formação histórica do Brasil está “marcada pela eliminação física do 'outro', ou 
por sua escravização, que também é uma forma violenta de negação de sua alteridade, os processos de negação do 'outro' também se dão no plano das representações e no imaginário social" (Candau, 2013, p. 17).

A educação precisa estar voltada para a inclusão das diferenças, e Imbernón (2016) ressalta a importância de compreender sobre o multiculturalismo, que seria reconhecer a sociedade como "plural e diferenciada e a necessidade de agir de maneira respeitosa, mas também é a promoção das diferentes culturas. Não é diluir as culturas diversificadas, e sim respeitá-las e compartilhá-las. Respeitar as estrangeiras, mas também as nativas" (p. 69). O autor também destaca que a cultura escolar não foi pensada para a multiculturalidade de indivíduos, mas sim para a generalização, tendo como caráter um modelo assimilacionista, "privando um grupo de seu direito de ser educado com as mesmas garantias que os cidadãos" (Imbernón, 2016, p. 71). Mas como mudar as atitudes dos professores e a organização institucional que, muitas vezes, reforçam a exclusão de muitos estudantes no contexto escolar e reproduz de forma padronizada a cultura social dominante? Neste trabalho defendemos uma perspectiva intercultural da educação, conforme a defendida por Candau (2013), a qual precisa estar voltada para o reconhecimento do "outro", baseada no diálogo entre os diferentes grupos sociais e culturais, portanto, num movimento de negociação cultural, em um contexto caracterizado pela assimetria de poder.

A visão intercultural, em nossa perspectiva, precisa estar presente no contexto escolar, no sentido de reconhecer as diferenças, sem negá-las ou naturalizá-las, mas indo ao encontro das discussões realizadas anteriormente sobre as duas ações indissociáveis e complementares que são o cuidar e o educar. Candau (2013) destaca que é fundamental que haja um reconhecimento das identidades culturais, e que esta identificação pode se iniciar desde os primeiros anos do processo escolar, no sentido de buscar as raízes culturais das famílias dos(as) estudantes e das suas vidas sociais, como, por exemplo, o bairro no qual vivem, as comunidades a que pertencem, quais instituições frequentam, etc., com o propósito de valorizar as diferentes características de cada pessoa ou grupo social e cultural.

A autora também destaca sobre a importância de "desvelar o daltonismo cultural" que está presente na escola. Este daltonismo se caracteriza por não reconhecer as diferenças presentes na escola, como as de ordem étnica, de gênero, de origem social e regional, etc., e não destacar a riqueza dessa diversidade na sala de aula. Consideramos que esta situação ocorre, porque, muitas vezes, os(as) professores(as) não possuem preparo para trabalhar com estas questões da diferença, e por acreditar que a forma mais correta é tratar todos como iguais, um grupo padrão. Assim, muitas vezes, ao naturalizar as diferenças, elas acabam sendo silenciadas, e não são consideradas como desafios para uma prática educativa problematizadora e significativa para os estudantes. Moreira e Candau (2007) explicam que o daltonismo acaba impedindo que professoras e professores reconheçam a "presença da diversidade (e de suas consequências) na escola" (Moreira \& Candau, 2007, p. 31). 
No contexto escolar também é possível observar a discriminação, o racismo, os quais assumem diferentes manifestações. Por esse motivo, professores e professoras têm como papel fundamental criar espaços para que as relações sejam interculturais de forma positiva, o que não elimina os conflitos. O objetivo é que os(as) estudantes se coloquem no lugar do outro, e que as situações de preconceito, discriminação e racismo presentes na escola não sejam banalizadas, mas sim problematizadas, em momentos de reflexão coletiva, a partir de situações reais que se apresentam na escola. Para Silva (2014), “a educação em direitos humanos só encontrará terreno profícuo à medida que as identidades, as narrativas e os saberes não hegemônicos também encontrarem acolhimento no currículo e nas práticas pedagógicas", e complementa que "a igualdade de condições e de direitos depende de que a escola reconheça radicalmente a pluralidade que nela se manifesta" (p. 47). Como consequência, deveria gerar uma mudança no enfoque de currículo, porque este deveria ter como objetivo a formação de sujeitos de direitos. Nesse sentido, a escola "deve promover, em termos pessoais e coletivos, a formação de sujeitos de direito capazes de conhecer, reivindicar e lutar por seus direitos" (Silva, 2014, p. 48).

É necessário destacar sobre a importância de "conceber a prática pedagógica como um processo de negociação cultural" e, neste sentido, considera-se que, para que isso ocorra, é importante evidenciar a "ancoragem histórica-social dos conteúdos”. Ou seja, o conhecimento que se é trabalhado na escola, precisa ser visto como histórico, e não apenas como fatos e conceitos, adquirindo, na maioria das vezes, legitimidade social e se transformando em verdades absolutas. A escola está formada tendo por "base a afirmação de conhecimentos considerados universais, uma universalidade muitas vezes formal que, se aprofundarmos um pouco, termina por estar assentada na cultura ocidental e europeia, considerada como portadora da universalidade" (Candau, 2013, p. $33)$.

O currículo, portanto, não pode negar as identidades e os pertencimentos não hegemônicos. É necessário compreender que "a promoção de uma cultura dos direitos humanos exige a revisitação do currículo e da própria cultura escolar hegemônica, historicamente baseada na ideia de universalidade dos conhecimentos e dos sujeitos da educação" (Silva, 2014, p. 43). Mas a questão do multiculturalismo surge para repensar a questão do universalismo, questionando sobre que tipo de universalidade. No entanto, também não se pode reduzir ao relativismo absoluto, limitando o conhecimento apenas a um universo cultural, o que levaria a "negar a própria possibilidade de construirmos algo juntos, negociado entre os diferentes" (Candau, 2013, p. 33). Nesta perspectiva, Candau (2013) defende a ideia de que é importante:

[...] desvelar o caráter histórico e construído dos conhecimentos escolares e sua íntima relação com os contextos sociais em que são produzidos. Obriga-nos a repensar nossas escolhas, nossos modos de construir o currículo escolar e nossas categorias de análise da produção dos nossos alunos(as). (Candau, 2013, p. 33).

$\mathrm{Na}$ visão intercultural, o currículo abarca diferentes universos culturais e, nesse 
sentido, é importante "reescrever o conhecimento escolar" (Moreira \& Candau, 2007, p. 32). Os autores explicam que é necessário que:

[...] os interesses ocultados sejam identificados, evidenciados e subvertidos, para que possamos, então, reescrever os conhecimentos. Desejamos que o aluno perceba o quanto, em Geografia, os conhecimentos referentes aos diversos continentes foram construídos em íntima associação com o interesse, de certos países, em aumentar suas riquezas pela conquista e colonização de outros povos. (Moreira \& Candau, 2007, p. 32).

Moreira e Candau (2007) destacam que nos anos iniciais do ensino fundamental também é possível mobilizar os(as) estudantes para:

[...] reescrever conhecimentos, saberes, mitos, costumes, lendas, contos. Inúmeras histórias infantis, por exemplo, têm sido reescritas com base no emprego de pontos de vista distintos dos usuais. $\mathrm{O}$ caso dos Três Porquinhos pode surpreender se a figura do Lobo representar o especulador imobiliário que tão bem conhecemos. As atitudes da Cigarra e da Formiga podem ser reavaliadas, tendo-se em mente a forma como se concebem e se organizam trabalho e lazer na sociedade contemporânea. (Moreira \& Candau, 2007, p. 34).

Nesse sentido, a ideia dos autores não é substituir um conhecimento pelo outro, mas-contribuir para que os(as) estudantes entendam as relações de poder que estão presentes na hierarquização dos saberes e nas manifestações culturais. Nesta perspectiva, é importante "conceber a escola como espaço de crítica e produção cultural" (Candau, 2013, p. 35), ou seja, a escola é um espaço em que estão presentes e são produzidas as diferentes expressões culturais e as diferentes linguagens. Assim, os(as) docentes precisam favorecer experiências de produção cultural e de ampliação do horizonte cultural dos alunos e alunas, aproveitando os recursos disponíveis na comunidade escolar e na sociedade. E, para que isso ocorra, a escola precisa estar aberta para as diferentes manifestações da cultura popular, e também para a cultura erudita. Neste sentido, "músicas populares, danças, filmes, programas de televisão, festas populares, anúncios, brincadeiras, jogos, peças de teatro, poemas, revistas e romances precisam estar presentes em salas de aula" (Moreira \& Candau, 2007, p. 41). Como também, os conhecimentos mais próximos dos grupos dominantes, com o objetivo de ampliar o repertório dos estudantes, para que exista, portanto, uma interação entre essas culturas. Nesse caso, o objetivo "é que a cultura dos estudantes e da comunidade possa interagir com outras manifestações e outros espaços culturais como museus, exposições, centros culturais, música erudita, clássicos da literatura” (Moreira \& Candau, 2007, p. 41). Assim, os autores destacam que, para que isso ocorra, é necessário que o(a) professor(a) enquanto intelectual seja um "crítico cultural” em relação à cultura em que está imerso(a). Nesta visão, a escola precisa organizar suas propostas pedagógicas, a fim de questionar o que parece natural no contexto social. Nesse sentido, é importante que o estudante compreenda a ordem social da qual faz parte, desafiando, dessa forma, o existente. "Podem não mudar o mundo, mas podem permitir que o aluno o compreenda melhor” (Moreira \& Candau, 2007, p. 42). 
Portanto, este processo de crítica se faz necessário para que se repense as concepções que estão implícitas nos componentes culturais, quais ensinamentos e formas de pensar estão presentes, e problematizar essas questões que são fundamentais para que os estudantes tenham uma formação ética, política e crítica, conforme sugerem as Diretrizes Nacionais para a Educação em Direitos Humanos (MEC, 2012).

De acordo com o documento supracitado, é importante que no currículo escolar sejam contemplados conteúdos que estejam articulados com a realidade social, ambiental, política e cultural, e que estes dialoguem com as realidades próximas e vivenciadas pelos estudantes de forma crítica e reflexiva.

A partir das discussões realizadas, compreendemos sobre a importância de uma educação intercultural, a qual tem como cerne a consideração do "outro" na prática pedagógica, bem como, nas relações estabelecidas na escola. Candau (2013) apresenta várias questões que precisam ser repensadas quando se reflete sobre o currículo, que tem por base o multiculturalismo e uma Educação em Direitos Humanos. E estas questões precisam ser levadas em conta ao desenvolver os conteúdos de Ciências Naturais nos anos iniciais do ensino fundamental, sendo esta a discussão realizada no próximo tópico.

\section{O Ensino de Ciências Naturais, os Direitos Humanos e a Cidadania}

De acordo com Lorenzetti e Delizoicov (2001), é importante que as crianças, desde os anos iniciais, possam ter acesso ao conhecimento científico para desenvolver uma melhor compreensão sobre situações que fazem parte do seu cotidiano e para que possam tomar decisões mais adequadas no seu contexto social. Nesse sentido, o ensino de ciências tem uma função importante "na vida das pessoas, pois pode proporcionar aos alunos conhecimentos mínimos para garantir as necessidades humanas, bem como, saúde e questões ambientais. Quanto mais informado e atento aos problemas está o cidadão, mais sucesso ele terá nas tomadas de decisões" (Soares et al., 2013, p. 51).

Em relação ao exercício da cidadania, Viecheneski e Carletto (2013) destacam que:

Cabe ressaltar que atitudes e valores se constroem desde cedo e quando a escola proporciona momentos para debates, questionamentos, reflexões, exposição e confronto de ideias, abre a oportunidade de ensinar valores essenciais ao exercício da cidadania, como respeito pelas diferentes ideias, tolerância, cooperação, respeito à diversidade, às regras combinadas em grupo, capacidade de se comunicar, de ouvir e esperar sua vez para se expressar, responsabilidade, senso crítico e inclusão social. (Viecheneski \& Carletto, 2013, p. 223).

Portanto, entende-se que o ensino de Ciências Naturais não pode ficar restrito ao repasse de informações e ao preenchimento de questionários, mas, precisa ser realizado considerando as diversidades existentes em sala de aula. Para isso, os(as) professores(as) deveriam criar um ambiente propício para as crianças se posicionarem, para questionarem, para perguntarem, para observarem, para investigarem e para resolverem situações problemas. Um ensino baseado em experiências, que tragam sentido para as 
crianças, promovendo a construção de conhecimentos. Ensinar ciências, nesta etapa "é de suma importância, pois é nesse período que a criança constrói, aprimora e reconstrói conceitos sobre si mesma e sobre o mundo a sua volta, relacionando o que lhe é ensinado na escola ao que observa e aprende no seu cotidiano" (Porto \& Porto, 2012, p. 29).

Entendemos que um dos objetivos das Ciências Naturais é que a criança ressignifique seus conhecimentos e amplie sua visão de mundo, e que possa tomar decisões no seu contexto social, buscando melhor qualidade de vida. Neste caso, a melhor qualidade de vida se refere às situações do dia a dia da criança, como, por exemplo, ter consciência sobre uma alimentação saudável, compreender sobre a importância da preservação da natureza, e assim podemos citar: a separação do lixo de forma adequada; conhecer como seu corpo está estruturado e como ele deve ser respeitado e cuidado, compreender as diferenças individuais, sociais e culturais; e saber respeitar essas diferenças, etc. Questões que precisam ser compreendidas e que vão influenciar decisões futuras e desenvolver formas de se viver no contexto social.

O ensino de Ciências Naturais nos anos iniciais do ensino fundamental também precisa discutir questões relacionadas aos impactos da Ciência e da Tecnologia para a sociedade e o ambiente. De acordo com Fabri e Silveira (2013), “o professor, juntamente com a sua turma, precisa abordar temas curriculares pertinentes, que fazem parte da vivência de seus alunos e, a partir daí, desenvolver um trabalho relacionando à Ciência e à Tecnologia, seus impactos, suas vantagens e desvantagens" (p. 79).

Nesse sentido, quando o(a) professor(a), por exemplo, desenvolver o conteúdo Água, em sala de aula, ele(a) poderá discutir conceitos importantes como água no planeta, identificar a água nos seres vivos, no solo, no ar, nos oceanos, e em outros lugares; os diferentes estados da água no planeta; o ciclo da água, etc. Também poderá discutir questões voltadas à geração de energia, como, por exemplo, as construções das usinas hidrelétricas e o quanto essas construções podem trazer consequências negativas para o ambiente no qual está sendo construída, tanto para as pessoas que ali vivem como, também, para os outros seres vivos que habitam a região. Assim, discute-se as vantagens dessas construções, no sentido de gerar a energia elétrica para as pessoas, mas também suas desvantagens para o meio ambiente. Avaliamos que estas discussões são importantes quando se buscar uma Educação em Direitos Humanos, porque é fundamental se ter um meio ambiente ecologicamente equilibrado, a fim de garantir que outros direitos humanos não sejam violados, como saúde, bem-estar, alimentação, trabalho, etc., compreendendo a indivisibilidade dos direitos humanos.

Fabri e Silveira (2013) ressaltam, também, que há a necessidade de uma educação científica que prepare o (a) estudante para compreender sobre o:

[...] avanço científico e tecnológico refletindo sobre os impactos, em condições de se posicionar de maneira consciente e responsável diante das situações que emergirem ao seu redor, desde os anos iniciais até níveis superiores, transformando os saberes do senso comum em conhecimentos mais elaborados. (Fabri \& Silveira, 2013, p. 79).

Portanto, compreendemos o ensino de Ciências como fundamental para 
contribuir para que os estudantes tenham:

[...] formação crítica e reflexiva frente às decisões e discussões atuais que envolvem os conhecimentos científicos e tecnológicos, suas causas, consequências, interesses econômicos e políticos, tornou-se parte das funções que a escola pode desempenhar já o início da educação fundamental. $\mathrm{O}$ ensino de ciências nesta etapa escolar pode contribuir com a inserção do aluno em uma atmosfera de compreensão da realidade que o rodeia a partir de uma perspectiva que favoreça a contextualização dos conhecimentos científicos, baseada na concepção de ciência como produção humana. (Oja \& Bastos, 2013, p. 5).

Portanto, compreender a realidade, a partir de discussões voltadas para as decisões relacionadas aos conhecimentos científicos e tecnológicos, as causas e consequências, desvelar os interesses que estão envolvidos nestas decisões, deve ser iniciada nos anos iniciais do ensino fundamental, contribuindo para a formação de indivíduos mais críticos e reflexivos.

A Educação em Direitos Humanos tem como foco promover a educação para a mudança e à transformação social. Sendo que seu objetivo principal é "a formação para a vida e para a convivência, no exercício cotidiano dos Direitos Humanos como forma de vida e de organização social, política, econômica e cultural nos níveis regionais, nacionais e planetário". E que esse objetivo deverá ser o caminho para as instituições de ensino organizarem suas ações de Educação em Direitos Humanos, "adequadas às necessidades, às características biopsicossociais e culturais dos diferentes sujeitos e seus contextos" (MEC, 2012, p. 1).

Consideramos, a partir desse objetivo central da Educação em Direitos Humanos, que os(as) professores(as) precisam compreender o que são Direitos Humanos, seus princípios e como estes se articulam com os conteúdos desenvolvidos em sala de aula; além disso, desenvolver práticas que promovam uma aprendizagem ativa por parte do(a) estudante. Partindo dessa premissa, consideramos que é fundamental que estas discussões na escola não ocorram apenas nas disciplinas das áreas sociais e humanas, mas também nas disciplinas relacionadas às Ciências da Natureza, como Ciências Naturais (nos anos iniciais do ensino fundamental), Física, Química e Biologia, porque compreendemos que é possível fazer a articulação dos conteúdos desses componentes curriculares com temáticas sociais.

Partindo desse pressuposto, compreendemos que é possível articular questões relacionadas aos Direitos Humanos nas aulas de Ciências, a fim de contribuir para que os estudantes desenvolvam valores e habilidades fundamentais para a construção de uma sociedade mais justa, democrática e inclusiva. Consideramos importante que as ações educativas no ensino de Ciências Naturais possam contribuir para que os estudantes construam "argumentos com base em dados, evidências e informações confiáveis e negociar e defender ideias e pontos de vista que promovam a consciência socioambiental e o respeito a si próprio e ao outro, acolhendo e valorizando a diversidade de indivíduos e de grupos sociais, sem preconceitos de qualquer natureza" (MEC, 2017, 
p. 324), indo ao encontro do que se espera em relação a uma Educação em Direitos Humanos. Avaliamos que nos anos iniciais é fundamental que as crianças possam ser ouvidas no contexto da sala de aula, no sentido do(a) professor(a) criar espaços para compreender os conhecimentos prévios dos(as) estudantes. Oliveira (2013) destaca que o professor precisa aprender a ouvir os(as) estudantes e trocar com eles(as) informações. E complementa que:

[...] ouvir não é fácil para quem não foi acostumado a isso! Será necessário treino e exercício por parte desse professor para aprender a ouvir realmente a voz do aluno. Ouvir o aluno não se encerra na reprodução das respostas que o professor quer ouvir, mas na possibilidade de o aluno expressar sua própria voz e, por consequência, sua visão de mundo. (Oliveira, 2013, p. 65).

Avaliamos ser fundamental, nas aulas de ciências naturais, a escuta sensível em relação às experiências que as crianças trazem para sala de aula, ou seja, dar valor às "experiências do viver" (Arroyo, 2013) das infâncias que fazem parte da escola. Arroyo (2013) destaca as diferentes vivências que as crianças poderão trazer nessas falas como as "vivências dos espaços físicos" onde vivem, como moradias, ruas, povoados, campo e outros; as "vivências de viver, sobreviver", como alimentação, trabalho da família, ou desemprego, os direitos que não são garantidos, como o direito à vida, à saúde, à alimentação, ao lazer, etc.; as vivências relacionadas à família, como, por exemplo, os diferentes arranjos familiares; às "vivências de proteção, cuidados ou desproteção", como o abandono, maus tratos, entre outras. Estas vivências podem e, em nossa opinião, precisam fazer parte das aulas de ciências, para que estas se tornem mais vivas, mais próximas das crianças. Sendo que uma das maneiras de compreender essas diferentes vivências e valorizá-las é dar voz para as crianças. O diálogo é a melhor forma de buscar e compreender essas vivências, e articulá-las aos conteúdos de Ciências Naturais, o que consideramos fundamental para uma educação voltada aos direitos humanos. No entanto, nem sempre essas "escutas" são fáceis de serem feitas, devido às situações precárias e, muitas vezes, desumanas que muitas crianças vivem em seu contexto social. Mas, avaliamos que não podemos ignorar essas vivências, sem explorá-las nas aulas de Ciências Naturais. Talvez uma das formas de envolver essas vivências nas práticas educativas seja ir além dos muros da escola, observar a comunidade que estas crianças estão inseridas, e realizar, por exemplo, projetos que possibilitem esta articulação. Para Chassot (2000), há uma "necessidade de se buscar uma valorização dos saberes populares e uma conscientização do respeito que os mesmos merecem e de como estão inseridos nos distintos contextos sociais" (p. 207).

A Base Nacional Comum Curricular (MEC, 2017) destaca que para desenvolver o letramento científico ${ }^{1}$ é necessário que a área de Ciências esteja articulada com outras áreas do saber. Partindo desse pressuposto, compreendemos que é possível articular

1 Nas diferentes pesquisas relacionadas ao ensino de ciências utilizam-se os termos alfabetização científica e letramento científico, neste artigo nos referimos ao letramento científico considerando “[...] a importância de preparar o indivíduo para a vida em uma sociedade científica e tecnológica, na qual o conhecimento assume um papel essencial, dentro de uma perspectiva crítica da ciência e da tecnologia” (Mamed \& Zimmermann, 2005, p. 1). 
questões relacionadas aos Direitos Humanos nas aulas de ciências, a fim de contribuir para que os(as) estudantes construam conhecimentos fundamentais para se ter uma sociedade justa, democrática e inclusiva, conforme sugere a BNCC. E, que, também os estudantes possam formar "argumentos com base em dados, evidências e informações confiáveis e negociar e defender ideias e pontos de vista que promovam a consciência socioambiental e o respeito a si próprio e ao outro, acolhendo e valorizando a diversidade de indivíduos e de grupos sociais, sem preconceitos de qualquer natureza" (MEC, 2017, p. 324, grifo nosso), indo ao encontro do que se espera em relação a uma Educação em Direitos Humanos.

O documento supracitado refere-se ao ensino não ser apenas baseado na apresentação dos conteúdos de Ciências Naturais para os(as) estudantes, mas é necessário que os(as) professores(as) planejem momentos para que estes(as) se envolvam nos processos de aprendizagem, principalmente aqueles processos que englobem a investigação, para que a partir daí ampliem sua curiosidade, exercitando a observação, o raciocínio lógico e a criatividade; a fim de sistematizar suas primeiras explicações sobre o mundo natural e tecnológico, e "sobre seu corpo, sua saúde e seu bem-estar, tendo como referência os conhecimentos, as linguagens e os procedimentos próprios das Ciências da Natureza" (MEC, 2017, p. 331).

É importante destacar que o ensino de Ciências Naturais é um direito da criança nos anos iniciais do Ensino Fundamental, como é preconizado pela Lei de Diretrizes e Bases da Educação Nacional no 9394/96 (Lei n. 9394, 1996). Neste sentido, cabe aos(às) professores(as) ampliarem os conhecimentos dos(as) estudantes, considerando a faixa etária com a qual trabalham, a partir de um planejamento adequado. Porque consideramos que, a partir do ensino de Ciências Naturais, é possível que o(a) estudante ressignifique seus conhecimentos, ampliando dessa forma sua visão de mundo, seu entendimento sobre o contexto em que está inserido, possibilitando-o a tomar decisões mais adequadas no seu cotidiano, como: escolher os alimentos que trazem benefícios para a saúde, sobre as decisões referentes aos cuidados com seu corpo, sobre os cuidados com o meio ambiente, compreender sobre as diferenças individuais, sociais e culturais, e saber respeitar essas diferenças, etc.

Na BNCC (MEC, 2017), no componente curricular Ciências Naturais, estão dispostas as unidades temáticas, os objetos de conhecimento e as habilidades referentes aos anos iniciais do Ensino Fundamental. Em relação aos anos iniciais, a partir da unidade temática, é possível e viável desenvolver temas que se relacionam com os Direitos Humanos e Cidadania. Em nossa concepção, estas temáticas precisam ir ao encontro dos objetivos para uma Educação em Direitos Humanos definidos pelas Diretrizes Nacionais para Educação em Direitos Humanos (MEC, 2012). Este documento define que uma das principais finalidades da defesa dos Direitos Humanos é a "construção de sociedades que valorizem e desenvolvam condições para a garantia da dignidade humana" (MEC, 2012, p. 503, grifo nosso). As Diretrizes explicam que uma Educação em Direitos Humanos tem como objetivo contribuir para que pessoas ou grupos sociais 
reconheçam os seus direitos, e que também sejam capazes de exercê-los no contexto social, bem como respeitar os direitos dos outros. Outro objetivo da EDH é desenvolver a sensibilidade voltada para as "questões interpessoais, em que cada indivíduo seja capaz de perceber o outro em sua condição humana" (MEC, 2012, p. 503, grifo nosso). Partindo desse documento, que é um norteador para as ações voltadas aos Direitos Humanos nas instituições escolares, podemos identificar algumas temáticas, que compreendemos como importantes, para se buscar o entendimento sobre os direitos de todos e todas e também para desenvolver um olhar e uma escuta mais sensível para as questões da diferença, buscando, dessa forma, melhores e mais harmoniosas relações interpessoais. As temáticas que consideramos importantes de serem desenvolvidas nos anos iniciais no ensino de Ciências Naturais e que fazem interface com Direitos Humanos, são: Relações étnico-raciais; Educação Ambiental; Sexo, sexualidade e gênero ${ }^{2}$ Bullying. No entanto, consideramos que estas temáticas sejam fundamentadas em eixos estruturantes para que de fato os(as) estudantes possam compreendê-las e vivenciá-las em seu contexto educativo.

Consideramos que nesta etapa de ensino é possível articular os conteúdos de ciências com as temáticas pontuadas acima. Para exemplificar essas possíveis relações, selecionamos alguns objetos de conhecimentos definidos na BNCC (MEC, 2017) e propomos algumas sugestões para realizar essas articulações.

Em relação aos objetos de conhecimento denominados “Corpo humano e Respeito à diversidade", é possível discutir temáticas relacionadas às relações étnico-raciais com o propósito de compreender sobre as diferentes culturas e suas influências para a construção do nosso país; buscar as origens culturais dos(as) estudantes; identificar as diferentes manifestações culturais presentes na comunidade na qual a escola está inserida; reconhecer as diferentes características fenotípicas visíveis (a cor e a textura dos cabelos e da pele, altura, etc.); discutir conceitos como preconceito, discriminação e racismo, etc. A partir desses objetos de conhecimentos, o(a) professor(a) também poderá discutir questões sobre sexo, gênero e sexualidade, desenvolvendo discussões voltadas para o respeito às diferentes manifestações da sexualidade; às discriminações existentes no contexto brasileiro em relação ao gênero, e isso poderá ser feito a partir de dados estatísticos (tabelas, gráficos) que demonstrem que, ainda, em nosso país mulheres possuem salários inferiores em relação aos homens; à presença da mulher na ciência; à violência em relação às mulheres; empoderamento feminino, e outras.

2 Leal et al. (2017) explicam que o conceito de sexo se refere tanto aos órgãos reprodutores, como a suas características biológicas e cromossômicas, sendo assim, são questões biologicamente construídas, e complementam que "a diferenciação dos sexos se inicia biologicamente, e a partir daí a sociedade, o registro civil, as famílias moldam de acordo com seu reconhecimento sexual" (Leal et al., 2017 p. 96). A sexualidade faz parte da vida das pessoas "envolvendo aspectos individuais, sociais, psíquicos e culturais, que carregam historicidades, práticas, atitudes e simbolizações” (Moizés \& Bueno, 2009, p. 206). Já gênero está relacionado às questões sociais "nas quais compreende a diferenciação social entre as pessoas, sendo a possível construção e desconstrução, pois, é a partir de padrões históricos e culturais que definimos comportamento de mulheres e de homens" (Leal et al. 2017, p. 96). 
A temática bullying ${ }^{3}$ também poderá ser contextualizada na sala de aula, a partir desses objetos de conhecimento, como, por exemplo, o respeito às diferenças, às características pessoais, culturais, religiosas, etc., o porquê ocorre o bullying, quais são suas características, que tipos de bullying existem, etc. A partir dos objetos de conhecimento "Nutrição do organismo e Hábitos alimentares", é possível articular questões relacionadas aos diferentes tipos de alimentos que são originários de diferentes culturas; entender como os hábitos alimentares são influenciados pela cultura a que pertencemos, como a forma de usar talheres, ou não usá-los, de se comportar à mesa, etc., dando ênfase às Relações étnico-raciais.

A temática Educação Ambiental poderá estar presente quando o(a) professor(a) for desenvolver os objetos de conhecimentos "Ciclo hidrológico, Consumo consciente $e$ Reciclagem", pois poderão ser discutidas questões sociais consideradas de urgência social, como o lixo, o seu descarte correto, o lixo eletrônico, o consumo e como este gera mais lixo em nosso contexto social, poluição das águas e a necessidade de sua preservação para a saúde das pessoas e de outros seres vivos, saneamento básico enquanto direito, e outras discussões que se fizerem necessárias. Ressaltamos que estas temáticas poderiam se articular entre si, ou seja, o(a) professor(a) poderá discutir as questões ambientais relacionadas à cultura indígena, por exemplo, ou a temática do bullying relacionada à questão da homofobia. Nesse sentido, para que essas articulações e discussões sejam possíveis, é fundamental que os(as) docentes, nesta etapa de ensino, compreendam sobre essas temáticas e que também possibilitem que as vivências das infâncias sejam ouvidas e consideradas nestas discussões.

A partir de Moreira (2002); Moreira e Candau (2007), Candau (2008; 2013), Candau e Sacavino (2013); e mediante o documento Diretrizes Nacionais para a Educação em Direitos Humanos (MEC, 2012), propomos alguns eixos estruturantes que entendemos serem importantes de estarem presentes nas discussões voltadas para os Direitos Humanos e sua articulação com o ensino de Ciências Naturais, nos anos iniciais do Ensino Fundamental, para uma formação humana. Esses eixos são: i) Sensibilizar-se no reconhecimento das diferenças sociais, culturais e econômicas; ii) Reconhecer-se como cidadão (ã) de direitos e respeitar o direito do "outro"; iii) Planejar e desenvolver práticas inclusivas; iv) Valorizar a inter-relação entre seres humanos e ambientes naturais.

O eixo Sensibilizar-se no reconhecimento das diferenças está atrelado à ideia discutida por Moreira e Candau (2007) e Candau (2013) sobre o "daltonismo cultural". Para estes autores, é necessário o reconhecimento das diferenças em relação ao gênero, à condição social, física, cultural e étnica na escola, as quais precisam ser problematizadas na sala de aula. Neste sentido, é fundamental que ocorra a articulação da diferença e igualdade. Nesta perspectiva, é importante que, nesta etapa de ensino, haja momentos que sejam voltados para a sensibilização, no sentido de se colocar no lugar do outro, de

3 Intimidação sistemática quando há violência física ou psicológica, intencional e repetitiva que ocorre sem motivação evidente, praticado por indivíduo ou grupo, contra uma ou mais pessoas, com o objetivo de intimidá-la ou agredi-la, causando dor e angústia à vítima, em uma relação de desequilíbrio de poder entre as partes envolvidas. (Lei no. 13.185, de 6 de novembro de 2015). 
perceber as diferenças que existem na escola. Consideramos que é importante destacar, nesta etapa de ensino, o respeito às diferenças, salientando sobre o respeito ao próximo e à tolerância. Entendemos que a tolerância tem um papel fundamental para as relações humanas serem mais harmônicas. Assim, se pode compreender que a "tolerância é a harmonia na diferença” (Unesco, 1995, p. 11). Isso significa que:

[...] a tolerância é o respeito, a aceitação e o apreço da riqueza e da diversidade das culturas de nosso mundo, de nossos modos de expressão e de nossas maneiras de exprimir nossa qualidade de seres humanos. É fomentada pelo conhecimento, a abertura de pensamento, de consciência e de crença. (Unesco, 1995, p. 11).

Portanto, sensibilizar os estudantes a reconhecer e respeitar as diferenças, nesta etapa de ensino, contribui para que esses repensem atitudes e comportamentos, muitas vezes, vivenciados nas próprias famílias ou em outras instituições nas quais fazem parte, principalmente na escola. Por isso, consideramos importante desenvolver a prática da tolerância. "A prática da tolerância significa que toda pessoa tem a livre escolha de suas convicções e aceita que o outro desfrute da mesma liberdade" (Unesco, 1995, p. 12).

Assim, a sensibilização, o reconhecimento, e o desenvolvimento da tolerância e do respeito às diferenças pode se iniciar nas primeiras etapas da educação básica por meio de livros de literatura infantil, a partir de poemas, músicas, vídeos, rodas de conversa, teatros, os quais poderão ser bons disparadores para essas discussões. $\mathrm{O}$ trabalho pedagógico com os conteúdos de Ciências Naturais, como, por exemplo, a questão do corpo, de gênero, das diferentes manifestações da sexualidade, as diferenças pessoais, como físicas e culturais, são conteúdos que se apresentam no componente curricular Ciências Naturais, os quais poderão ter como eixo estruturante a sensibilização, o reconhecimento, o respeito e a tolerância às diferenças. Porque desenvolver debates, discussões e reflexões, tendo como princípio esse eixo, possibilita ampliar o conhecimento dos estudantes em relação à diferença e à identidade, questões importantes que devem estar presentes no currículo.

O eixo reconhecer-se como cidadão(a) de direitos e respeitar os direitos do "outro" está atrelado à ideia de que se faz importante nas discussões sobre Direitos Humanos, a partir de conteúdos de Ciências Naturais, abordar os direitos sociais, políticos, econômicos, culturais e civis. No sentido de que as crianças tenham compreensão sobre esses direitos e que estabeleçam relações com questões mais amplas da sociedade. Também é importante que as discussões em sala de aula tenham como objetivo o reconhecimento do "outro", indo ao encontro do primeiro eixo discutido, que é perceber que todos os indivíduos possuem direitos, independentemente de sua etnia, condição econômica, social, cultural, gênero, etc., conforme previsto na Constituição Federal de 1988. No entanto, compreender a assimetria social também faz parte da educação, dando ênfase para uma formação política, no sentido de que todos têm direitos iguais, mas nem todos tem acesso a esses direitos, devido a vários fatores, como históricos, sociais, econômicos e políticos. Isso pode acontecer nos anos iniciais do ensino fundamental, como, por exemplo, com a análise de dados estatísticos, os quais podem ser problematizados 
pelos professores(as) para que as crianças possam constatar que os direitos são iguais e assegurados pelas normas jurídicas, mas que no contexto real nem sempre estes direitos são respeitados devido a vários fatores. Para problematizar com os estudantes, pode-se levantar questões, como, por exemplo: "O que podemos fazer para diminuir a desigualdade salarial entre homens e mulheres no mundo do trabalho?" Nesse sentido, é fundamental que as realidades vividas pelos(as) estudantes sejam desveladas, e para isso os(as) professores(as) deverão ter uma escuta sensível às vivências que eles(as) trazem para sala de aula.

Para um trabalho pedagógico voltado para os direitos humanos e cidadania, é fundamental que haja a articulação dos conceitos de preconceito, de discriminação e de racismo, contribuindo para que os estudantes entendam sobre a importância de ações inclusivas no contexto social e também na instituição escolar, indo ao encontro do terceiro eixo estruturante que é planejar e desenvolver práticas inclusivas. Consideramos que conceitos como preconceito, discriminação e racismo precisam ser problematizados nas salas de aula por meio de diversos recursos, como, por exemplo, tirinhas que podem possibilitar reflexões sobre preconceito e discriminação, teatro organizado pelas crianças e o(a) professor(a); livro de literatura infantil, entre outros. Nesta perspectiva, é importante que os estudantes dos anos iniciais do ensino fundamental, por meio de conteúdos de Ciências Naturais, possam compreender que preconceito é um préjulgamento, tratando-se, portanto, "de uma opinião ou sentimento que adotamos irrefletidamente, sem fundamento ou razão" (Borges, et al., 2009, p. 53). Para esses autores, os preconceitos estão presentes no processo de socialização e é muito difícil erradicá-los do pensamento. No entanto, compreendemos que na escola é importante que sejam desveladas as questões de preconceito, as quais, muitas vezes, geram conflitos e atitudes agressivas em relação aos outros.

Problematizar esses conceitos contribui para que os estudantes tenham mais discernimento para identificar práticas preconceituosas e discriminatórias no contexto social, nas falas dos(as) colegas e professores(as), e também nas produções culturais e midiáticas, como propagandas que depreciam a figura da mulher, músicas que apoiam o racismo, etc.; enfim, estas discussões contribuem para que seja valorizada a pessoa humana. Nesse sentido, "essa pessoa, por suas características naturais, por ser dotada de inteligência, consciência e vontade, por ser mais do que uma simples porção de matéria, tem uma dignidade que a coloca acima de todas as coisas da natureza" (Lodi, 2003, p. 16). Assim, o respeito à dignidade humana precisa estar presente nas relações, em todos os espaços e de maneira igual para todas as pessoas (Lodi, 2003), pois a preservação da dignidade faz parte dos direitos humanos. Este eixo busca também problematizar questões voltadas à violência, que está presente nos contextos escolares, como, por exemplo, o Bullying, que pode ser considerado como um tipo de violência escolar, de acordo com Candau (2013). Portanto, é fundamental que a escola seja um ambiente promotor de direitos humanos, a partir do "reconhecimento da necessidade de respeito às diferenças, garantindo a realização de práticas democráticas e inclusivas, livres de 
preconceitos, discriminações, violências, assédios e abusos sexuais, dentre outras formas de violação à dignidade humana" (MEC, 2012, p. 504).

Consideramos que o eixo planejar e desenvolver práticas inclusivas aproxima-se de dois conceitos importantes que precisam estar presentes na educação básica, são eles: o cuidar e o educar. $\mathrm{O}(\mathrm{A})$ professor(a) também precisa estar atento(a) a estes conceitos nas escolas e desenvolver ações inclusivas para que as crianças da etapa dos anos iniciais possam vivenciar o que é um ambiente inclusivo, livre de preconceito, discriminação, racismo e violência, ou seja, um ambiente acolhedor, propício para se alcançar os direitos de aprendizagem, no qual haja a valorização das diferenças, o que vai ao encontro do primeiro e segundo eixos discutidos. Compreendemos que esses eixos precisam fundamentar as discussões sobre Direitos Humanos no Ensino de Ciências Naturais, contribuindo para uma formação ética, política e crítica como define as Diretrizes Nacionais para a Educação em Direitos Humanos (MEC, 2012).

$\mathrm{O}$ eixo estruturante valorizar a inter-relação entre seres humanos e ambientes naturais e a importância de um ambiente saudável tem relação com o princípio "Sustentabilidade Socioambiental", discutido nas Diretrizes Nacionais para a Educação em Direitos Humanos, que destaca sobre o "incentivo e promoção de um desenvolvimento sustentável que preserve a diversidade da vida e das culturas, condição para a sobrevivência da humanidade de hoje e das futuras gerações" (MEC, 2012, p. 503). Consideramos que este eixo também se articula com o que é definido na Constituição Federal de 1988, a qual preconiza que "o direito de um ambiente ecologicamente equilibrado, bem de uso comum do povo e essencial à sadia qualidade de vida, impondo-se ao poder público e à coletividade o dever de defendê-lo e preservá-lo as presentes e futuras gerações" (Constituição Federal, 1988). A partir das questões acima citadas, compreende-se que o aspecto social não está desvinculado das questões ambientais. Nesse sentido, Tiriba e Profice (2014) destacam que o meio ambiente deixou de ser apenas o assunto de cientistas, pois faz parte dos movimentos sociais que por consequência "deram nova direção ao pensamento ambientalista, sobretudo na definição de prioridade de luta. Atualmente as desigualdades sociais são consideradas como um dos mais graves problemas ambientais a serem enfrentados por pessoas, povos e nações" (p. 57). Portanto, é importante refletir sobre as questões voltadas às desigualdades socioeconômicas quando se trata de educação ambiental.

Sendo assim, consideramos que os conteúdos desenvolvidos nos anos iniciais do ensino fundamental, no componente curricular Ciências Naturais, podem se articular com as questões voltadas aos valores sociais e humanos e ao respeito à diversidade de vida. Assim, é possível o(a) professor(a) desenvolver práticas que aproximem a criança da natureza, no sentido de as mesmas compreenderem a importância de se viver em harmonia com o meio natural e, sobretudo, que compreendam sobre a importância de se ter um ambiente saudável como um direito humano. Aproximar a criança da natureza significa fornecer condições para que ela se sensibilize em relação ao mundo vivo, e poderá ser uma forma de contribuir para que as gerações futuras sejam mais 
comprometidas com os problemas ambientais. "Se as crianças não interagem com a natureza fica comprometida sua afinidade com ela, a atribuição de seu valor, seu apelo afetivo, sua condição de fonte de conhecimento" (Tiriba \& Profice, 2014, p. 65). Nesta perspectiva, consideramos que os professores que atuam neste componente curricular promovam práticas que possibilitem a vivência e o contato da criança com a natureza, permitindo que a mesma tenha experiências com os elementos naturais, como a água, a terra, o ar, por meio de organização de aulas-passeios em espaços verdes, a partir do planejamento da efetivação de hortas, jardins, por meio da observação de espaços naturais, etc. Também avaliamos que temáticas como as consequências negativas e positivas da ciência e tecnologia, como produções humanas, possam ser problematizadas neste eixo como discutimos anteriormente.

Também defendemos que as temáticas Sexo, Gênero e Sexualidade; Relações étnico-raciais; Bullying e Educação Ambiental, que fazem interface com os Direitos Humanos, podem ser desenvolvidas a partir dos diferentes conteúdos de Ciências Naturais nos anos iniciais do Ensino Fundamental, e que estas discussões precisam estar baseadas nos eixos estruturantes citados anteriormente. Consideramos também que estes eixos não devem ser tratados de forma estanque, mas articulados uns com os outros. Portanto, estes eixos dialogam entre si no sentido de contribuírem para a formação humana e cidadã.

De acordo com Oliveira e Queiroz (2016), a formação para a cidadania está atrelada à ideia de "desenvolvimento de valores sociais universalizáveis". Por isso, esses autores relacionam as áreas de Educação em Ciências e Educação em Direitos Humanos, e destacam que "para essa cidadania tão almejada, todas as demais áreas disciplinares devem buscar esse tipo de relação. A Educação em Direitos Humanos é Transversal à Educação" (p. 69).

Concordando com Oliveira e Queiroz (2016), consideramos que o trabalho pedagógico voltado para a Educação em Direitos Humanos e Cidadania precisa estar pautado na transversalidade, a qual pode ser compreendida como uma maneira de organizar o "trabalho didático-pedagógico em que temas, eixos temáticos são integradores às disciplinas, às áreas ditas convencionais de forma a estarem presentes em todas elas" (MEC, 2013, p. 29). No documento Diretrizes Nacionais para a Educação em Direitos Humanos (MEC, 2012) fica explícito que a organização dos currículos da Educação Básica, voltados para os conhecimentos referentes aos Direitos Humanos, poderá acontecer das seguintes formas: por meio da transversalidade, a partir de temas voltados para os Direitos Humanos e desenvolvidos de forma interdisciplinar; também pode se organizar um conteúdo específico, referente a uma disciplina específica do currículo; e de forma mista, que seria conciliar a transversalidade e a disciplinaridade.

A perspectiva que defendemos é o trabalho a partir da transversalidade, pois consideramos que é possível e viável articular os conhecimentos científicos com as temáticas sociais, as quais estão presentes na vida diária. Também defendemos que, além dessas temáticas serem desenvolvidas de forma transversal, a partir dos conteúdos 
de Ciências Naturais, é fundamental que as relações estabelecidas no contexto escolar sejam baseadas no respeito e na percepção do "outro", na tolerância e, sobretudo, baseada no cuidar e no educar, enquanto ações indissociáveis e complementares, as quais foram discutidas anteriormente. É importante ressaltar que as instituições escolares não são os únicos espaços voltados para educar as pessoas em Direitos Humanos, mas reafirmamos o que está explícito nas Diretrizes Nacionais para a Educação em Direitos Humanos, que estas instituições têm como "responsabilidade a promoção e legitimação dos seus princípios como norteadores dos laços sociais, éticos e políticos. Isso se faz mediante a formação de sujeitos de direitos, capazes de defender, promover e reivindicar novos direitos" (MEC, 2012, p. 503). Também avaliamos que a educação é uma "das mediações fundamentais para o acesso ao legado histórico dos Direitos Humanos, quanto para a compreensão de que a cultura dos Direitos Humanos é um dos alicerces para a mudança social" (MEC, 2012, p. 495). Dessa forma, a educação pode ser considerada como "um dos Direitos Humanos e a Educação em Direitos Humanos é parte fundamental do conjunto desses direitos, inclusive do próprio direito à educação" (MEC, 2012, p. 495).

\section{Considerações finais}

O objetivo desse artigo foi discutir sobre formas de articular temáticas voltadas para os direitos humanos, como Sexo, gênero e sexualidade, Bullying, Relações étnicoraciais e Educação Ambiental com os conteúdos de Ciências Naturais nos anos iniciais do ensino fundamental, numa perspectiva voltada para a formação humana. Diante desse objetivo inicial, propomos alguns eixos estruturantes para fundamentar as práticas realizadas pelos(as) professores(as), a fim de buscar uma educação em direitos humanos no ensino de Ciências Naturais. Os eixos estruturantes discutidos neste trabalho foram: Sensibilizar-se no reconhecimento das diferenças sociais, culturais e econômicas; Reconhecer-se como cidadão(ã) de direitos e respeitar o direito do "outro"; Planejar e desenvolver práticas inclusivas; Valorizar a inter-relação entre seres humanos e ambientes naturais. Destacamos que estes eixos não são estanques, pois eles se articulam e se complementam no momento da prática pedagógica do(a) professor(a). Consideramos também, que estes eixos não são estruturantes apenas no processo de ensino de Ciências Naturais, mas que nas ações e relações cotidianas estabelecidas na escola eles precisam estar presentes.

Acreditamos que esta pesquisa e as discussões realizadas, ao longo desse texto, podem contribuir para o ensino de Ciências, para que as práticas realizadas pelos(as) docentes no ensino de Ciências Naturais nos anos iniciais do ensino fundamental possam ser pautadas em uma visão mais ampla sobre os conteúdos que desenvolverão em sala de aula, e que, ao planejarem, possam considerar essas temáticas e os eixos estruturantes. Consideramos fundamentais essas discussões para o desenvolvimento de uma educação em Direitos Humanos, e avaliamos que muitas injustiças sociais presentes no contexto brasileiro não são resolvidas pela escola, enquanto instituição salvadora de todos os males, mas avaliamos fundamental que nestes espaços educativos sejam realizadas 
discussões sobre direitos humanos, no sentido de que os indivíduos envolvidos nesse processo possam desenvolver a capacidade de defender e exercer seus direitos, como também o de respeitar e estar em ação a favor dos direitos dos outros.

Também avaliamos que para desenvolver as temáticas Bullying, Relações étnicoraciais, Sexo, gênero e sexualidade e Educação Ambiental no ensino de Ciências Naturais é importante que a metodologia utilizada não seja voltada para o repasse de informações, mas que o professor possa desenvolver na sala de aula momentos para a reflexão e o diálogo. Portanto, a metodologia deverá ter como cerne a participação ativa dos(as) estudantes, tendo como princípios que estes(as) são construtores de seus conhecimentos de forma problematizadora, interativa, participativa e dialógica, portanto, dando ênfase para uma formação crítica.

Consideramos que, nos anos inicias do ensino fundamental, é importante que o(a) professor(a) desenvolva diferentes estratégias para que os(as) estudantes possam participar ativamente da construção do conhecimento voltado para as temáticas de Direitos Humanos e Cidadania. Nos anos iniciais do ensino fundamental é importante que o(a) professor(a) desenvolva práticas com diferentes linguagens, como música, teatro, vídeos, movimento, literatura, artes visuais, etc., as quais poderão ser disparadores para problematizar questões voltadas às temáticas que fazem interface com os Direitos Humanos e Cidadania no ensino de Ciências Naturais.

No ensino de ciências, para que o(a) professor(a) possa realizar essa relação com os conteúdos específicos deste componente curricular com as temáticas voltadas para os direitos humanos, é necessário que eles(as) compreendam sobre o que são direitos humanos e sua relação com a cidadania, e a relação da EDH para a formação de uma cultura da paz. Assim, consideramos importante que tenham formações específicas voltadas para problematizar questões relacionadas a este tema. Dessa forma, o resultado da discussão aqui empreendida poderá contribuir para a organização de formações continuadas baseadas em uma educação voltada para os direitos humanos, cidadania e Ciências Naturais, pois as temáticas apresentadas neste trabalho e os eixos estruturantes poderão colaborar para o planejamento dessas formações, no sentido de buscar uma visão mais ampla sobre os conteúdos de Ciências Naturais e suas possíveis articulações com uma educação voltada para a formação humana. Também consideramos que esta pesquisa poderá contribuir para a formação inicial de futuros pedagogos e pedagogas que atuarão nesta etapa de ensino, os quais, muitas vezes, são responsáveis em atuar nos diferentes componentes curriculares, como matemática, geografia, história, ciências, artes, etc., sendo essa uma especificidade desta etapa de ensino.

Nesta perspectiva, é essencial que discussões voltadas para a temática dos direitos humanos e da cidadania sejam realizadas nos cursos de formação inicial de professores e, também, nas formações continuadas para aqueles profissionais que já atuam na área da educação. Deste modo, os(as) professores(as) ou futuros docentes poderão ter a possibilidade de refletirem sobre seus conceitos, preconceitos, pensamentos, e sua forma de ver o mundo, os quais foram construídos no processo de socialização. 
Em relação às implicações para à área de Ensino de Ciências, destacamos que este estudo teórico aponta para a necessidade de pesquisas empíricas, no sentido de avaliar os eixos propostos neste trabalho e de se estabelecer limites e possibilidades da articulação entre o ensino de Ciências e Direitos Humanos visando uma formação para a cidadania, não apenas nos anos iniciais, mas também nos demais níveis de ensino.

\section{Referências}

Apple, M. W. (2005). Repensando ideologia e currículo. In A. F. B. Moreira \& T. T. Silva. da. Currículo, cultura e sociedade (pp. 39-58). Cortez.

Arroyo, M. G. (2013). Currículo, território em disputa. 5 ed. Vozes.

Borges, E., Medeiros, C. A., \& Adesky, J. d' (2009). Racismo, preconceito e intolerância. 7 ed. Atual.

Chassot, A. (2000). Alfabetização científica: Questões e desafios para a educação. Ed. UNIJUÍ.

Candau, V. M. (2008). Direitos humanos, educação e interculturalidade: As tensões entre igualdade e diferença. Revista Brasileira de Educação, 13(37), 45-56. https://doi. org/10.1590/S1413-24782008000100005

Candau, V. M. (2013). Multiculturalismo e educação: Desafios para a prática pedagógica. In A. F. Moreira \& V. M. Candau. Multiculturalismo: diferenças culturais e práticas pedagógicas (pp. 13-37). Vozes.

Candau, V. M. \& Sacavino, S. B. (2013). Educação em Direitos Humanos e formação de educadores. Educação. 36(1), 59-66.

Carvalho, L. O., Duarte, F. R., Menezes, A. H. N., \& Souza, T. E. S. (2019). Metodologia científica: Teoria e aplicação na educação a distância. 1 ed. Universidade Federal do Vale do São Francisco.

Fabri, F. \& Silveira, R. M. C. F. (2013). O ensino de ciências nos anos iniciais do ensino fundamental sob a ótica CTS: Uma proposta de trabalho diante dos artefatos tecnológicos que norteiam o cotidiano dos alunos. Investigações em Ensino de Ciências. 18(1), 77-105. Imbernón, F. (2016). Qualidade do ensino e formação do professorado: Uma mudança necessária. 1. ed. Cortez.

Leal, N. C. Zoccal, S. I. L., Saba, M., \& Barros, C. R. S. (2017). A questão de gênero no contexto escolar. (2017). Leopoldianum, (121), 95-104.

Lei no 9.394, de 20 de dezembro de 1996. (1996). Lei de Diretrizes e Bases da Educação Nacional. Estabelece as diretrizes e bases da educação nacional. Diário Oficial da União. Brasília, DF: Presidência da República. 
Lei no. 13.185, de 6 de novembro de 2015. (2015). Lei do Bullying. Institui o Programa de Combate à Intimidação Sistemática (Bullying). Diário Oficial da União. Brasília, DF: Presidência da República.

Lodi, L. H. (2003). Ética e cidadania: Construindo valores na escola e na sociedade. Secretaria Especial dos Direitos Humanos. MEC, SEF, SEMTEC, SEED.

Lopes, A. C., \& Macedo. E. (2011). Teorias do Currículo. 1 ed. Cortez, 2011.

Lorenzetti, L., \& Delizoicov, D. (2001). Alfabetização científica no contexto das séries iniciais. Revista Ensaio. 3(1), 45-61.

McCowan, T. (2015). O direito humano à aprendizagem e a aprendizagem dos direitos humanos. Educar em Revista. (55), 25-46.

Mamede, M., \& Zimmermann, E. (2005). Letramento Científico e CTS na formação de professores para o ensino de ciências. Enseñanza de las ciências, número extra. VII Congreso.

MEC (2012). Diretrizes Nacionais para a Educação em Direitos Humanos. Brasília: Secretaria da Educação Básica.

MEC (2013). Diretrizes Curriculares Nacionais Gerais da Educação Básica. Brasília: Secretaria da Educação Básica.

MEC (2017). Base Nacional Comum Curricular. Brasília: Secretaria da Educação Básica.

Moizés, J. S., \& Bueno, S. M. V. (2010). Compreensões sobre sexualidade e sexo nas escolas segundo professores do ensino fundamental. Revista da Escola de Enfermagem da USP, 44(41), 205-212.

Moreira, A. F. B., \& Candau, V. M. (2007). Indagações sobre o currículo: Currículo, conhecimento e cultura. Ministério da Educação. Secretaria de Educação Básica.

Moreira, A. F. B. (2002) Currículo, diferença cultural e diálogo. Educação \& Sociedade. Ano XXIII, 79, agosto, 15-38. http://dx.doi.org/10.1590/S0101-73302002000300003

Moreira, A. F. B., \& Silva, T. T. da. (2005). Sociologia e teoria crítica do currículo: uma introdução. In A. F. B. Moreira, \& T. T. Silva. Currículo, cultura e sociedade (pp. 7-38). Cortez.

Oja, A. J., \& Bastos, F. (2013). Ensino de ciências no início da educação fundamental: Algumas implicações para uma educação científica de qualidade. In Encontro Nacional de Pesquisa em Educação em Ciências (p. 1). Água de Lindóia, SP.

Oliveira, R.D. V.L. de., \& Queiroz, G. R.P.C.(Org.).(2016). O cotidiano, o contextualizado e a Educação em Direitos Humanos: A escolha de um caminho para uma Educação cidadã cosmopolita. In R. D. V. L. Oliveira \& G. R. P. C Queiroz. Tecendo diálogos sobre direitos humanos na educação em ciências (pp. 63-98). Editora Livraria da Física. 
Porto, A. \& Porto, L. (2012). Ensinar ciências da natureza por meio de projeto: Anos inicias do ensino fundamental. 1 ed. Rona.

Silva, A. T. R. da. (Org.). (2014). Educação em Direitos Humanos: o currículo entre o relativismo e o universalismo. In A. T. R. da Silva (Org.). Leituras críticas em Educação e Direitos Humanos (pp. 20-50). Liber Livro; Alia Opera.

Silva, T. T. da. (2005). Documentos de Identidade: Uma introdução às teorias do currículo. 2 ed. Autêntica.

Siqueira Júnior, P. H., \& Oliveira, M. A. M. de. (2010). Direitos Humanos e Cidadania. 3 ed. Revista dos Tribunais.

Soares, A. C., Mauer, M. B., \& Kortmann, G. L. (2013). Ensino de ciências nos anos iniciais do ensino fundamental: Possibilidades e desafios em Canoas-RS. Revista Educação, Ciência e Cultura, 18(1), 49-61.

Tiriba, L. \& Profice, C. (2014). O direito humano à interação com a natureza. In A. M. M. Silva, \& L. Tiriba (Org.). Direito ao ambiente como direito à vida: Desafios para a educação em direitos humanos (pp. 47-77). Cortez.

Unesco. (1995). Declaração de Princípios sobre a Tolerância. Conferência Geral da Unesco em sua $28^{\circ}$ reunião. Paris.

Viecheneski, J. P., \& Carletto, M. (2013). Por que e para quê ensinar ciências para crianças. Revista Brasileira de Ensino de Ciência e Tecnologia, 6(2), 213-227.

Hanslivian Correia Cruz Bonfim

${ }^{\circ}$ https://orcid.org/0000-0002-7833-871X Secretaria Municipal de Educação de Curitiba

Curitiba, Paraná, Brasil hansbonfim@hotmail.com

Orliney Maciel Guimarães

https://orcid.org/0000-0003-4762-4884

Universidade Federal do Paraná

Programa de Pós-Graduação em Educação

Curitiba, Paraná, Brasil

orli.guimaraes@gmail.com

Submetido em 12 de abril de 2020

Aceito em 14 de agosto de 2020

Publicado em 16 de setembro de 2020 